\title{
critical reviews
}

\section{Wright's Better Reasoning}

\section{Rita C. Manning California State College at San Bernardino}

Wright's Better Reasoning ${ }^{1}$ is a subtle and sophisticated treatment of argument analysis and language. It bears reviewing because of its sophistication, which is, while its great strength, a. possible source of confusion to the student and the instructor who uses it for the first time.

Wright is concerned in this text with two facets of reasoning: argument analysis and characterization. The first part of the book is devoted to argument analysis. This review will focus on Part One, for two reasons. The first is that I take argument analysis to be fundamental to good reasoning and hence, a good place to start with students. Part One includes enough material for a very full semester. The second reason is that Wright introduces, and exploits, the notion of the diagnostic argument in Part One. I think that this is an important contribution to the theoretical discussion of informal logic.

In Chapter One, Wright provides a fairly informal method of schematizing arguments. He suggests that, in most cases, we may content ourselves with separating out the conclusion from the support. He offers two series of exercises at the end of the chapter. One consists of review questions, which I found too difficult to use, and the other consists of exercises which require the students to identify arguments and to schematize them by identifying the conclusion and the supporting statements. The exercises are quite good, though there are not enough of them. They are in ordinary language and are complicated enough to challenge the students, though not so complicated that the average student is frustrated. In addition to providing practise in schematizing, some of the exercises can be used as examples of specific kinds of arguments which are introduced later in Part One.

Chapter Two is a discussion of the inductive/deductive distinction. Again, Wright contents himself with an informal characterization of deduction. According to Wright, an argument is deductive if, "the support claims become committed to the conclusion as a matter of language: implicitly or explicitly the conclusion is already contained within the support'.2
He introduces, in this chapter, a device which will become very important in Chapters Three through Five, and that is the notion of a rival conclusion. A rival conclusion is a conclusion which answers the same question as the conclusion given, and is incompatible with that conclusion. This becomes a very powerful tool of evaluation in later chapters. The introduction of rival conclusions also provides a way of making the inductive/ deductive distinction. An argument is deductive if all of the rivals, save one, are semantically eliminated by the support statements. Though this is an interesting characterization of the deductive argument, it does not provide a test which the students can use in determining whether a particular argument is deductive or inductive. The instructor will simply see, in many cases, that an argument is deductive, and will realize that there is only one rival in these cases and that is that the conclusion is false. The student is unable to recognize deductive arguments and hence will find the semantic eliminability test impossible to apply because he will not know whether he has an exhaustive list of rivals to begin with. This problem is especially acute when one notices that Wright has suggested in the same chapter, and rightly, that for an inductive argument, the list of rivals is limited only by practical considerations.

In this same chapter, Wright discussess two temptations which he thinks ought to be avoided. The one is to think that all deductive arguments are silly and trivial, and the other is to think that a deductive argument is to be preferred to an inductive argument in every case.

I think that he is correct to characterize this second temptation as an intellectual vice, and his discussion of it bears repeating here.

He remarks that any argument can be cast as an inductive or as a deductive argument. Consider, for example the argument contained in this passage:

Detective Casey mused over his findings. Mr. Feendish had been found hidden in a closet of the dead man's bedroom, with the deceased's blood all over his clothes.

When he was discovered, he confessed to the crime.

"Yes", Casey concluded, "We have our man".

Now we can reconstruct Casey's reasoning as an inductive or as a deductive argument. The inductive argument would be cast this way:

S-1 Mr. Feendish was found in a closet in the dead man's bedroom.

S-2 Mr. Feendish had the deceased's blood all over his clothes.

S-3 Mr. Feendish confessed to the crime.

C. Mr. Feendish committed the crime.

We can also cast Casey's reasoning deductively by adding to the schematization above a general claim of the following sort:

S.4 Whenever the suspect is found in a closet of the deceased's bedroom (or has the deceased's blood on his clothes, or confesses), the suspect committed the crime.

But S-4 is pretty obviously false. Hence, we ought not to attribute $S-4$ to our reasoner. In this case, we had better cast the argument inductively.

He now adds the admonition against giving in to the 
second temptation, the temptation to think all deductive arguments are silly and trivial. This temptation, by the way, doesn't even occur to the student until after he has mulled over Wright's admonition to give up the other temptation. After having said that inductive arguments are strong, when they are, in virtue of evidence, and that arguments are deductive when they have a semantic, not an evidential, guarantee, one wonders how serious he is about urging us to avoid this temptation. He gives us no examples, in this chapter, of non-trivial deductive arguments, so the reader is at a loss to imagine what he would take to be an example of an argument best cast deductively.

In the remainder of Part One, Wright is concerned with a particular type of inductive argument, the "diagnostic argument", which is an argument which has an explanation as its conclusion. His discussion of diagnostic arguments is the best part of the book. He develops several important ideas which all have a cash value when it comes to evaluating these arguments.

The first is the distinction between two different kinds of evidence, "trace-data" and "background". Trace-data is characterized both as traces of what happened and as part of what the conclusion must explain. Background is relevant information which does not need to be explained by the conclusion. He offers the following simple example on p. 52 :

S. 1 Rocco left Nova Scotia in a balloon.

S-2 The Atlantic was stormy.

S-3 His gondola was found a few days later, far at sea, swamped and empty

S- 3 is trace data; it must be explained by any conclusion which could be offered. S-2 and S-1 are background.

We can appeal to the notion of trace data to evaluate conclusions. Take this list of rival conclusion:

C-1 Rocco drowned at sea.

C-2 He was fortuitiously rescued. (p.53)

They both answer the question, "What happened to Rocc $\alpha$ " One of the tests for picking the best conclusion is how well it explains the trace data. This brings us to the next notion, plausibility ranking.

This is ranking the rivals in order of their plausibility. The rival which is number one on the plausibility ranking will not necessarily be the explanation. At early stages of an investigation, the rival which is at the top focuses the investigation. At a much later stage of the investigation, the rival which is pretty firmly established as number one in the ranking is taken to be the explanation. This introduces another way of looking at diagnostic arguments: as stages in an investigation. Wright now has developed an insightful, and fairly elaborate method for characterizing and evaluating investigations.

In Chapter IV, Wright uses the method developed in Chapter III and applies it to three kinds of arguments: cause arguments, testimony arguments and sample-topopulation arguments.

The diagnostic model works very well for cause arguments. Wright analyzes all casual arguments as involving an inference from a correlation to a cause. The correlation can be between two objects, states of affairs, or between two properties. His discussion focuses on correlations between properties which populations share, for example smoking and having lung cancer. The correlation is the trace data which is explained by the diagnostic conclusion, which is a casual explanation.

The diagnostic model also works well for samplepopulation inferences. The model works less well for testimony cases. I think that Wright should have deferred this discussion to Chapter $V$ and handled it as a possible fallacy (illegitimate appeal to authority).

The strength of the discussion of fallacies in Chapter $V$ is that Wright suggests that we can only characterize something ( a claim or an argument) as a fallacy by appeal to the larger context in which it comes up. He down not supply us with a list of mistakes to be avoided, but he offers guidelines which a student can appeal to in deciding whether a claim is fallacious in a particular context. For example, in his discussion of testimony, he suggests that we ought to ask several questions (including questions about motive and competence) before we accept testimony as evidence.

I want now to address one of the general questions which is suggested by Part One. Wright does not attempt to justify his emphasis, in Part One, on diagnostic arguments, but one such reason does suggest itself. Wright may believe that all inductive arguments have a diagnostic component. This is a view which has been argued by Gilbert Harman. ${ }^{3}$ This is an intriguing possibility and I wish that Wright had addressed it head on. He hints at such a view in a section of Chapter III called "non-diagnostic induction". There he analyzes arguments with predictions and recommendations as conclusions as having a diagnostic step. Whether or not Harman's claim is correct, Wright might defend a more modest claim and that is that diagnostic arguments play a central role in reasoning. Perhaps an introductory text is not the place to defend this view, but I would be interested in seeing Wright address this question.

II

Part Two is an extended treatment of language. The moral is that language is a very complex and sophisticated tool and that we must be extremely sensitive to the context in which words or sentences are uttered. He offers some detailed examples which illustrate this thesis and a corresponding thesis that we will misunderstand each other if we insist on viewing language as a simple and mechanical tool.

I am very much in sympathy with the view taken in Part Two, and I think that it has important philosophical consequences. It is perhaps beyond the scope of an introductory informal logic course, but would, I think, serve as a very good text for an intermediate course.

III

While I would recommend Wright to anyone who wanted to focus on inductive arguments in ordinary language in an informal logic course (and I think that this should be our emphasis), the book does suffer from a number of failings which can defeat the unwary student and instructor.

It is typical, I think, of books that describe skills, to be 
easy reading for the skilled and nearly impossible reading for the novice. This book shares this trait to some extent. First, the book is not as effectively organized as it could be. Difficult material, which could be left out or deferred till later, is mixed in with simpler material. Second, the exposition is not easy. My students sometimes complain that there are too many "big words". This is not a complaint which worries me very much, though. I think that the students can follow the discussion with the aid of a dictionary.

Third, Wright does not provide the students with simple, one-sentence characterizations of key terms. The students need this kind of assistance.

None of the difficulties is insurmountable. The book would be better if it were better organized, provided simple characterizations of key terms and left out some of the graphics, which are nearly indecipherable in some cases.

The instructor who wants to use the book in its present form can leave out some of the difficult material and can provide simple characterizations of terms. Unfortunately, it is difficult to do these things beforehand. I can give one general piece of advice and that is to be far less ambitious in organizing the course than you are initially inclined to be. In ten very full weeks, we cover Chapters I, II, III, V, and parts of IV.

\section{Notes}

1. Larry Wright, Better Reasoning: Techniques for Handling Argument, Evidence and Abstraction (Holt, Rinehart and Winston, 1982). Pp. $x, 321$.

2. Ibid., p. 21.

3. See, for example Chapter 8 in Thought (Princeton University Press, 1973)'

Rita C. Manning, Department of Philosophy, California State College at San Bernardino, San Bernardino CA 92407.

\section{Fogelin's Understanding Arguments}

\section{G.A. Spangler California State University Long Beach}

The Second Edition of Understanding Arguments: An Introduction to Informal Logic (1982) by Robert Fogelin is an improved version of the earlier edition and remains, in my judgement, one of the best texts on the market for a beginning course in informal logic, or "critical thinking" as it is sometimes called. In this discussion note I should like to make some critical comments about the first few chapters of the book with a view to provoking interested teachers of informal logic to reflect (and perhaps write) about ways to consolidate advances in the philosophy of language with the teaching of our subject.

The first two chapters of Understanding Arguments explicate in a form suitable for freshman college students some of the work of Austin and Grice. Chapter One is largely concerned with speech acts and performatives; Chapter Two, a new chapter, takes up Grice's theory of conversational implication. The third chapter, entitled "The Language of Argument," gives an informal account of the notion of an argument and takes up the issues of standard form, validity, truth, and soundness, together with some discussion of argumentative moves such as assuring, hedging, and discounting. Since the typical focus of informal logic courses is on argumentation, the first two chapters are quite reasonably seen as prefatory and preparatory, but as such they are no less important than any Grundlagen.

As readers of Austin well know, before we criticize what someone is doing, we must first get clear about what is being done. We don't criticize a musician who is tuning his instrument in the way that we would if he were playing a melody. This is as obviously true in the case of discourse as it is elsewhere, but students often come to our classes in the belief that (a) speech and writing have a single purpose (the communication of ideas) and that (b) there is only one dimension of criticism open to them as critics (true/false) and only two possible outcomes of criticism (assent/denial, or better, perhaps: acceptance/rejection).

This inclination may be due to instruction or assimilation, but it is also a reflection, I think, of their congnitive development as students, what William G. Perry, Jr., calls the position of Dualism: "Good versus Bad, Right versus Wrong, We versus They, All that is not success is Failure, and the like."' Since part of what we want to accomplish as teachers of critical thinking skills is to move students from the position of thinking that right answers exist somewhere for every question (and the Authorities have them) to a more sophisticated position in which it is seen that diversity is not only possible but possibly reasonable, we must make it plain that we can do more than one thing 
with words and that the kids of criticism available are many and various. To this end a study of speech acts and conversational implicature is salutary. But one of the worst consequences of disabusing students of the view that there is one right answer to every question is what Perry calls "Multiplicity," the position that since there is no single Right Answer "everyone has a right to his own opinion." Diversity of opinion is here seen as a multiplicity of unrelated beliefs which are legitimate just because they are held; reasonableness goes out the window with Right Answers.

My students got the point, from the first two chapters of the text, that the evaluation of discourse is more complex and multifaceted than they thought or even anticipated, but in the face of this complexity it is tempting to retreat or escape into something even worse than the initial position. I looked forward to the next chapter on argument as providing a means to bring order and purpose to what must have appeared to some students as a jumble of hopeless complexity and irrelevance ${ }^{2}$.

Of course, I may exaggerate to some extent the difficulty my students felt, and I don't want to make too much of Perry's scheme. But it does help to make sense of comments I expect every teacher of philosophy and informal logic hears at the end of the third week or so: "Well, what is the answer?"; "I feel as though we aren't getting anywhere-what's the point?"; "There are so many different opinions! How is a person supposed to decide?" And so on

In my course I am using the "hot topics" approach, as Michael Scriven has called it. In addition to going through the text and textual exercises, my sludents are exploring the debate about the death penalty, a topic they (to my surprise) chose from among many they proposed. I divided the class into nine groups of five students, and they set about researching the topic and preparing pro and con cases. They found this exciting and useful, as I learned from critiques of the course I asked them to submit at the end of the first month. But they also found the issue to be vastly more complex than they had imagined. Some said they found their own views to be based on false beliefs about empirical matters, and that there were "too many" arguments to consider. It seemed to me that most began doing the assignment with the picture that the support for a position is a monofilament cable, but came to see it as a rope braided from many strands.

There was also some criticism of the text which. interestingly enough, amounted to an objection that it was sometimes "too simple." For instance, in the second chapter Fogelin introduces the notion of a pragmatic (versus speech) act, a counterpart of Austin's notion of a perlocutionary (versus performative) act. In discussing this section of the text we came to see that "pragmatic acts" (persuading, convincing) are really achievements reached by performing speech acts. Thus, the speech act of issuing a warning is aimed at warning someone, i.e., aierting someone to a danger or an untoward consequence of a certain course of action. This discovery gave rise to a discussion of the various avenues open to a speaker in reaching an objective, e.g., wheedling and cajoling versus giving reasons. This distinction provided a framework for appraising various uses of slanting and assuring, as well as of advertising techniques one finds in print and visual media. in general, there was an air of adventure and excitement in the class. By using ideas from the text to criticize it and other textbooks they brought with them to class, they could see that what they were learning had an application.

There was also considerable anxiety, both on my part and among the students. This was, perhaps, the natural result fo seeing the force of a simple idea giving way to something intricate. Also, criticism of a text usually has an unsettling effect on students who expect it to have Right Answers, and my students were unexceptional informal in this regard. For my part, Because I had resolved to try an exclusively informal approach in this course, I had nothing like the propositional calculus I could drage out to "solve everything" (or even use for "fancy footwork"), so I was no longer an Expert. Also, many classes were taken up with what one might call "freestyle analysis," an activity at which one can be more or less skilled but for which there are no rigorous canons, as there are for, say, determinig whether something is a wwt. Freestyle analysis gives rise to anxiety because students cannot be given a list of appropriate canons to master and because teachers don't know quite what to expect from the class.

When we did get to the chapter on argument, informed the class that I was dissatisfied with the account of argument given the re. 1 also reported that, in correspondence with the author of our text, I had come to see a way of improving it. During the summer I had written to Professor Fogelin to say that the discussion at the start of Chapter III conflicted with centra! points in the first two chapters. The relevant part of the text reads as follows:

Arguments are not statements, yet they are constructed out of statements. Now let's ask a very simple question: What words turn a batch of statements into an argument? Suppose we start with a simple list of statements:

Socrates is mortal.

All men are mortal.

Socrates is a man.

This is not an argument, but we can turn it into an argument by the use of the single word "therefore":

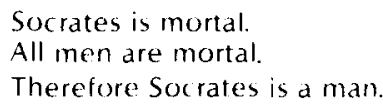

Perhaps this account would do in some contexts, but following as it does upon Austinian style philosophy of language it won't do. The second list of statements is no more an argument (or less of one) than the first, especially in view of the list's being referred to alternatively as a "batch." Indeed, it is not easy, though not impossible, to see how such a list of statements might come to be. If, for example, the initial list is a list of statements, let us say statements some one person has made, then they might be a list of statements a person made in the course of giving an argument. But if this list does not constitute an argument, then neither does the second list. Either list could be a list of statements some speaker has made that happen to correspond with the statements in an example of an argument in a logic textbook.

Again, either list could have been assembled randomly from the statements made by people in a certain room on a given day. Since the list is said to be a list of statements (as opposed to sentences, on the one hand, and, say, assumptions, on the other), one is led by the earlier chapters to ask why someone is making these statements and to what end are they being made.

Fogelin's suggestion about avoiding this difficulty goes 
as follows: ${ }^{4}$ let us speak of lists of sentences and series of statements. Then we can draw a distinction between a series of statements and an argument. "This difference," he writes, "is reflected in the sentences used to express a series of statements can be formulated in a list of sentences. On the other hand, special markers are needed to indicate that the sentences are being used to express an argument. These markers I call warranting connectives. We employ sentences containing warranting connectives to formulate or express arguments. It is for this reason that warranting connectives indicate the existence of arguments and serve as a guide to the structure of arguments."

Since it is possible to express an argument using sentences that contain no warranting connectives, warranting connectives are best seen as a linguistic resource speakers can draw upon to make it clear that an argument is being expressed. However, if, as Fogelin says, we want to draw a distinction between a series of statements and an argument, warranting connectives won't do the trick. Smoke is an indicator of fire, but we cannot distinguish some cases of fire from other things by virtue of the presence of smoke, as a race car driver would be quick to point out. This fact dovetails neatly with a lesson from chapter one: some words, "explicit performatives," indicate that a certain speech act is being performed, but the presence of such a word in the sentence uttered is neither necessary nor sufficient for the performance. Just as I can draw a conclusion without saying "therefore" or "hence" I can apologize without saying "I apologize." Nevertheless, it is often useful to take advantage of these resources to disclose explicity what I am doing so as not to be misunderstood.

My general worry about the chapter on argument is that the ideas of the first two chapters are not reinforced; in some instances they seem to have been dropped. The emphasis is initially, in the first two chapters, on action and purpose. Both the notion of a speech act and the notion of conversational implicature are teleological. The account of an argument as a series of statements is nonteleological, as is the notion of a warranting connective. Indeed, a warranting connective is a sentential element and, for all the good that "statement" does, one might just as well say that an argument is a series (sequence?) of sentences which are used to say something true or false. An argument is something constructed for a purpose whose parts are "connected" only in the uninteresting sense that they are related to one another somehow. What is important is the nature of the relationship, which is functional and has to do with the purposes of speakers in contexts. In this sense, when we speak in an informal logic course of arguments as a series of statements connected in various ways, or statements whose connectedness is indicated by various expressions, we are like travelers to a natural forest who bring with them TV sets and city shoes. These notions, and their attendant difficulties, belong to formal logic.

Beginning students in informal logic courses often have difficulty identifying arguments and here, too, the idea that arguments are series of statements can be unhelpful and sometimes misleading. This is particularly important when, after a brief account of arguments, the student is introduced to Arguments in Standard Form. We know perfectly well that arguments are seldom ever found outside textbooks in this refined form, that more often than not conclusions are given before premises are stated, and that arguments, when we meet them in their usual guises, are often hard to identify. They seldom look like a "series of statements." I am not suggesting that Standard Form has no place in a textbook, but I think it has to be emphasized that this is a device (a format) for restating arguments for a special purpose or purposes, and that pedagogically, it may be more helpful to introduce this scheme after we have gotten students to identify arguments in their natural settings.

Another point to consider here (and this is an objection, really, that could be leveled against many texts) is that the conception of an argument as a series of statements could be used to help students to construct arguments, but this is seldom done. In putting an argument together it can be helpful to lay out one's premises and conclusion in the Standard Form. After all, a critical thinker is not just a critic of arguments. ${ }^{5}$ Here, too, however, I think a teleological approach is best: I think we usually start by thinking that something is true and then seeing if we can make a case for it. We don't usually discover that we've got an argument for something and then just lay it out.

In Fogelin's Chapter III, after introducing Standard Form and the familiar triad, Validity, Truth, and Soundness, the text takes up a number of argumentative components (hedging, slanting, discounting, etc.) which are used to get at the structure of an argument by means of a labelling procedure. I had a great deal of success with this procedure by having students label these components in editorials from a local newspaper, the Los Angeles Times. My students seemed amazed to find so many instances of slanting and hedging in this respectable paper, and I quickly discovered that they believed all their labeling to be a form of criticism. We then had some lively and helpful discussions about the differences between indentifying an argumentative move and cirticizing it, and students came to see that mere labeling (thoughtless labeling) is useless (as the text warns). Again, we found it helpful to ask teleological questions: "What is the writer trying to accomplish?"; "What means is the writer using?"; Are the means defective or excessive?" In asking these questions, a critic can come to see, for example, that a writer is discounting in order to clear the ground for presenting his own view, i.e., he can see that discounting is subordinated to his principal task and, perhaps, coordinated with other sub-moves in the language game of arguing.

The idea of an argument as a series of statements "connected" in various ways leaves out of the story of argumentation its most important character, viz., the arguer and his purposes. This is particularly striking in a text which begins the tale by focusing on just this feature of discourse in general. I do not, at the moment, have a fully-worked-out alternative; I suspect that we need some counterpart here of the "speaker's reference"/ "semantic reference" distinction being entertained elsewhere. ${ }^{6}$ I hope that my comments are suggestive, at least, and provacative, at best. Teaching informal logic with Fogelin's text has been extremely rewarding for me and, I hope, for my students as well. My aim here is to stimulate discussion about a fine book. In this sense, what I have left unsaid is more important than what I have said.

\section{NOTES}

1. William G. Perry, Jr., "Cognitive and Ethical Growth: The Making of Meaning," The Modern American College, 
edited by A.W. Chickering and Associates (Jossey-Bass. 1981), pp. 76-116.

2. What is most useful about Perry's scheme is his account of the transitions from position to position. The scheme helps not only to identify "where students are coming from" but also in stimulating thought about ways to help them progress.

3. Understanding Arguments, p. 38.

4. Professor Fogelin made this suggestion in a letter to me and I do not know whether he would still abide by it. That this is not his published view should be borne in inind throughout.

5. I am reminded of this point by my colleague, Al Hayward, who also uses Fogelin's text and who has made inany helpful suggestions to me about its use.

6. See, for example, the papers by Donnelin and Kripke in Contemporary Perspectives in the Philosophy of Language, edited by Peter A French et al (The University of Minnesota, 1979).

Professor G. A. Spangler, Department of Philosophy, California State University, Long Beach, California 90840.

\section{abstract}

\section{The Speech Acts of Arguing and Convincing in Externalized Discussions \\ Journal of Pragmatics 6 (1982) 1-24 North-Holland Publishing Company}

F.H. van Eemeren and R. Grootendorst

In discussions directed towards solving a conflict of opinion the participants try to convince one another of the acceptability or unacceptability of the opinion that is under discussion. If the participants are co-operative, this means that they are prepared to externalize their position with regard to the opinion and to advance argumentation for or against it. In this article, which is a condensed translation of an article originally published in Dutch (Eemeren and Grootendorst 1980), the authors try to indicate, by reference to the speech act theory, what this entails.

In the way in which it was originally conceived, the speech act theory is inadequate to characterize argumentation. In the author's view this objection can be met by regarding argumentation as an illocutionary act complex at a textual level. They formulate the conditions obtaining for a happy performance of this act complex and explain that for the speaker the performance is linked by convention to the perlocutionary act of convincing. In the case of an externalized discussion this means that with his argumentation the speaker tries to make the listener, in turn, perform an illocutionary act in which he expresses his acceptance or non-acceptance of the opinion. announcements

\section{Second International Symposium On Informal Logic}

\author{
University of Windsor \\ Windsor, Ontario
}

June 20-23, 1983

The First International Symposium on Informal Logic was held in Windsor in 1978. The Second will assess the results of the past five years' work in informal logic, see what definition the field has achieved, take stock of the present battery of problems and methods, and chart the course for future development.

\section{Program}

Monday, June $20 \quad 1: 30$ p.m. Opening Session

"Informal Logic: The Last Five Years"

J. Anthony Blair \& Ralph H. Johnson (Windsor)

3:15 p.m. Plenary Session

"Needed: A Better Theory of Argument"

Trudy Govier (General Studies, Calgary)

8:00 p.m. Address

"The Logic of Deep Disagreements"

Robert Fogelin (Dartmouth)

Tuesday, June $21 \quad 9: 00$ a.m. Concurrent Sessions

A. Missing Premises

" 'Missing' or 'Hidden' Premises?"

James Gough (Waterloo) \& Christopher Tindale (Wilfrid Laurier)

"Filling Premise-Gaps in Arguments"

David Hitchcock (McMaster)

B. Formal vs. Informal Logic?

"Typing"

John Hoaglund (Christopher Newport College)

"Possible Worlds and Imagination in Informal Logic" John Nolt (Tennessee)

11:15 a.m. Plenary Session

"Background Logic: Its Significance in Informal Logic" Richard Paul (Sonoma State) 